\title{
Developing low-cost tags: assessing the ecological impacts of tethered tag technology on host species
}

\author{
Jesse F. Senko ${ }^{1,2, *}$, William M. Megill ${ }^{3,4}$, Louise B. Brooks ${ }^{5}$, \\ Robert P. Templeton ${ }^{3}$, Volker Koch $^{6,7}$ \\ ${ }^{1}$ School for the Future of Innovation in Society, Arizona State University, Tempe, AZ 85287, USA \\ ${ }^{2}$ School of Life Sciences, Arizona State University, Tempe, AZ 85287, USA \\ ${ }^{3}$ Ocean Technologies Laboratory, Department of Mechanical Engineering, University of Bath, Bath BA2 7AY, UK \\ ${ }^{4}$ Faculty of Technology and Bionics, Rhine-Waal University of Applied Sciences, 47533 Kleve, Germany \\ ${ }^{5}$ Moss Landing Marine Laboratories, Moss Landing, CA 95039, USA \\ ${ }^{6}$ Departamento de Ecología Marina, Centro de Investigación Científica y Educación Superior de Ensenada, 22860 Ensenada, \\ Baja California, Mexico \\ ${ }^{7}$ Deutsche Gesellschaft für Internationale Zusammenarbeit (GIZ) GmbH, 53113 Bonn, Germany
}

\begin{abstract}
Understanding and mitigating potential effects of tags on instrumented animals is a crucial consideration when developing new tracking techniques. Some populations of aquatic megafauna spend the majority of their lives occupying small home ranges, yet conventional finescale tracking methods generally provide a limited number of non-continuous locations, while new technology is cost prohibitive. We developed a low-cost tethered telemetry system $(<185$ USD $\operatorname{tag}^{-1}$ ) for short-term tracking of marine turtles in nearshore environments that incorporated standard GPS data loggers and VHF transmitters into buoyant tags of 3 different designs. We then estimated the drag of each tethered tag using an instrumented flow tunnel, deployed them on freeliving green turtles along Mexico's Baja California peninsula, and compared movement patterns of turtles equipped with high- and low-drag tags. All tags provided high-resolution tracks that ranged from 5.2 to $184.0 \mathrm{~h}$ (mean $\pm \mathrm{SD}=43.2 \pm 37.8 \mathrm{~h} ; \mathrm{h}=26$ turtles) for a total of $1122 \mathrm{~h}$. We found that the first 2 tag designs increased drag on large juveniles at typical swimming speeds by approximately 7 to $10 \%$, which is comparable to predicted drag increases incurred by similarly sized green turtles from most commercially available electronic tags. By contrast, the third tag design increased drag by $1 \%$ or less. Turtles fitted with the high-drag tags made fewer course changes and exhibited straighter (less tortuous) movements than those fitted with the low-drag tags. Although it is unclear if the observed behavioral differences were due entirely to the tags, our results highlight the importance of evaluating potential ecological impacts of telemetry devices on host species, particularly when developing new technology.
\end{abstract}

KEY WORDS: Animal movements · Animal tags $\cdot$ Behavior $\cdot$ Hydrodynamic drag $\cdot$ Megafauna Sea turtle $\cdot$ Tagging $\cdot$ Tracking

\section{INTRODUCTION}

Understanding the spatial ecology of long-lived aquatic megafauna is crucial for conservation planning (Seminoff et al. 2002, Peckham et al. 2007, Senko et al. 2010a,b, Gaos et al. 2012a,b, Wood et al. 2017).

\footnotetext{
${ }^{*}$ Corresponding author: jesse.senko@asu.edu
}

Most marine turtles are highly migratory, yet some populations spend the majority of their lives in coastal foraging and developmental habitats where they occupy limited home ranges and are exposed to multiple anthropogenic threats (Seminoff et al. 2002, Seminoff \& Jones 2006, Peckham et al. 2007, Senko

(C) The authors 2019. Open Access under Creative Commons by Attribution Licence. Use, distribution and reproduction are unrestricted. Authors and original publication must be credited. 
et al. 2010a,b, 2014, Gaos et al. 2012a,b, Mancini et al. 2012, Denkinger et al. 2013, Koch et al. 2013, Wood et al. 2017). High fidelity to small home ranges underscores the need for high-resolution data at fine spatial and temporal scales.

To track marine turtles at fine spatial scales, researchers have traditionally used non-satellite (i.e. radio and acoustic) tracking techniques (e.g. Seminoff et al. 2002, Southwood et al. 2003, Makowski et al. 2006, Seminoff \& Jones 2006, Taquet et al. 2006). Although these methods can generate high-accuracy data, they generally only provide a limited number of points in space as animals are tracked manually or pass by recording stations. This limitation can hinder the ability to accurately overlay movement data with important habitat features or spatially explicit threats at the required high resolution.

Satellite telemetry, which employs the Argos system, allows for remote tracking of marine turtles. However, this method is only accurate on a range of a few kilometers and, although now widely used, remains cost prohibitive (Godley et al. 2003, Hazel 2009, Costa et al. 2010). GPS technology is an alternative satellite-linked system that provides much better spatial accuracy than Argos but has historically been ineffective to track fine-scale movements of marine turtles in populations that surface too briefly for complete acquisition of satellite information (Hazel 2009). Over the past decade, increased sophistication of modern GPS technology has made it possible to obtain high-resolution tracks by providing quicker acquisition time (Schofield et al. 2007, 2009, 2010, Hazel 2009, Costa et al. 2010, Dujon et al. 2014, Hays et al. 2014). However, the high cost of these tags precludes their broad use and limits sample sizes for many projects (Weber et al. 2013). For example, Fastloc GPS tags designed for marine turtles typically range in price from 23000 to 5000 USD, depending on configuration (Wildlife Computers pers. comm.). Additionally, no matter how fast the tags can lock onto satellites from the surface of the water, there is no GPS technology currently available which can geolocate from a submerged depth of more than a few centimeters. Studies of the underwater movements of submerged animals have therefore had to rely on tags equipped with inertial measurement units which use dead reckoning based on double integrals of the accelerations of the animal's body to reconstruct the underwater tracks. These devices are expensive, and their accuracy is limited by the incremental error inherent in the double integration process, particularly with slow-moving animals whose body accelerations are small.
As researchers continue to develop new tracking techniques, it is necessary to understand and mitigate potential impacts on host species (Jones et al. 2013). Attaching tags to animals and subsequently tracking them may cause physical injury and suffering as well as lead to acute and chronic effects on important behavioral and physiological processes such as energy assimilation, foraging, predator avoidance, migration, mating, and reproduction (Hamelin \& James 2018). Several studies have demonstrated that tags can substantially increase the hydrodynamic drag on instrumented marine megafauna (Watson \& Granger 1998, Hanson 2001, Wilson et al. 2004, Hazekamp et al. 2010, Jones et al. 2013). Although a recent study from Cyprus revealed no significant differences in metrics of growth and reproductive output between tracked and non-tracked adult female green turtles Chelonia mydas and loggerhead turtles Caretta caretta (Omeyer et al. 2019), drag increases from tags have resulted in seemingly detrimental behavioral changes to other sea turtles and marine megafauna (Hanson 2001, Wilson et al. 2004, Fossette et al. 2008, Sherrill-Mix \& James 2008, Byrne et al. 2009, Hazekamp et al. 2010, Jones et al. 2013). Moreover, experiments using species-specific fiberglass casts of marine turtles in a wind tunnel demonstrated that drag increases from commercially available electronic tags can be substantial for immature animals (e.g. $>20$ and $>100 \%$ for turtles of 30 and $15 \mathrm{~cm}$ straight carapace length [SCL], respectively; Jones et al. 2013).

Here, we developed a low-cost method $(<185$ USD $\operatorname{tag}^{-1}$ ) for short-term, fine-scale tracking of marine turtles in shallow, nearshore environments and assessed its potential ecological impacts on host species. The technique does not require the animal to be tracked manually or pass by recording stations, like radio or acoustic tracking, and can provide high-resolution data that are accurate to $<10 \mathrm{~m}$. We incorporated a standard GPS data logger and a VHF transmitter into custom-made floating tags of 3 different designs. These devices were then attached to freeliving green turtles using a fail-safe tether at 2 nearshore foraging areas off the Pacific coast of Baja California Sur, Mexico (BCS). Specifically, we (1) describe the development of each tag iteration, (2) measure drag increase incurred by turtles from the tags in the laboratory, (3) assess the potential effects of highand low-drag tag designs deployed on turtles at the same location, and (4) provide recommendations for future tag development. Our expectation was that in areas where there are no clear navigational landmarks, such as our study site, turtles equipped with 
the high-drag tags would be tugged by them. We hypothesized that turtles fitted with both tags would turn equally often, but that movement patterns with the high-drag tags would correlate more closely with the current (i.e. be more 1-dimensional).

\section{MATERIALS AND METHODS}

\subsection{Tag design and development}

We designed 3 types of tags, each of which consisted of a GPS unit and a VHF transmitter inserted into a buoyant waterproof container and tethered to the turtle (Fig. 1). The GPS unit allowed us to follow the turtle's movements, while the VHF receiver allowed us to monitor the turtle and retrieve the tag without needing to recapture the animal. An orange flag was attached to each tag to facilitate visual location and recovery. With each new iteration, we improved the hydrodynamics of the design.

The hull of the first tag iteration consisted of a clear acrylic plastic cylinder $(15 \mathrm{~cm}$ long $\times 7 \mathrm{~cm}$ in diameter; $509 \mathrm{~g}$ total package). We placed a handheld GPS device (Garmin Mariner or Geko) in the cylinder and epoxied a small VHF transmitter (model F1835B, ATS) to the aft end of the top side of the unit. The GPS devices were configured to record their location every 2 min and could record positions for up to $12 \mathrm{~h}$. Both units had a reported positional accuracy of $<5 \mathrm{~m}$ by the manufacturer. The top $8.5 \mathrm{~cm}$ of a $591 \mathrm{ml}$ plastic soda bottle was epoxied over the bow of the cylinder to improve hydrodynamics. A lead-weighted polycarbonate keel $(15 \times 15 \mathrm{~cm})$ with drilled holes was used to stabilize and improve directional stability. Tracking devices were deployed on 13 free-living green turtles in 2003 at Estero Banderitas (EB), BCS (Table 1). We included this tag design to demonstrate tag devel- opment and performance but excluded tracking data from all movement analyses because turtles equipped with this tag (first tag-iteration) were tracked at a different location than the 2008 (second tag-iteration) and 2010 (third tag-iteration) animals.

The second tag iteration consisted of a hand-carved self-righting floating buoy made of balsa wood $(26 \times$ $9 \mathrm{~cm} ; 250 \mathrm{~g}$ total package). We placed a GPS data logger (20 channel EM-408 SiRF III receiver with antenna and MMCX, $35 \times 36 \mathrm{~cm}$, SparkFun Electronics) and a VHF transmitter (model F1835B, ATS) inside the floating tag. Before placing the GPS device in the tag, the outer protective casing was removed, and the manufacturer's internal battery was replaced with an 8000 mAh lithium polymer rechargeable battery pack to extend its recording duration. The units were configured to record location every $5 \mathrm{~min}$ for up to $120 \mathrm{~h}$ with a reported positional accuracy of $10 \mathrm{~m}$ by the manufacturer. The GPS unit was sealed first in a soft Ziploc® freezer bag to protect it from saltwater intrusion and then vacuum sealed into a more robust vinyl vacuum bag to make the package more durable. The underside of the tag was carved into the shape of a boat hull, with square chines and V-shaped prow. The weight was distributed within the tag so that it would float slightly down by the stern. The tag was equipped with a rudder to stabilize it in yaw and pulled from a steel ring placed low on the bow. Tracking devices were deployed on 6 free-living green turtles in 2008 at Laguna San Ignacio (LSI), BCS (Table 1).

The third tag iteration again consisted of a handcarved self-righting floating buoy made out of balsa wood $(23 \times 2.5 \mathrm{~cm} ; 100 \mathrm{~g}$ total package). The hull was carved to resemble a small kayak. Three holes were drilled in the top of the buoy to allow for a lid to be affixed using two $6 \mathrm{~mm}$ dowels in the forward holes (secured with electrical tape), and a straw was used to lift the VHF antenna higher from the rear hole. Three
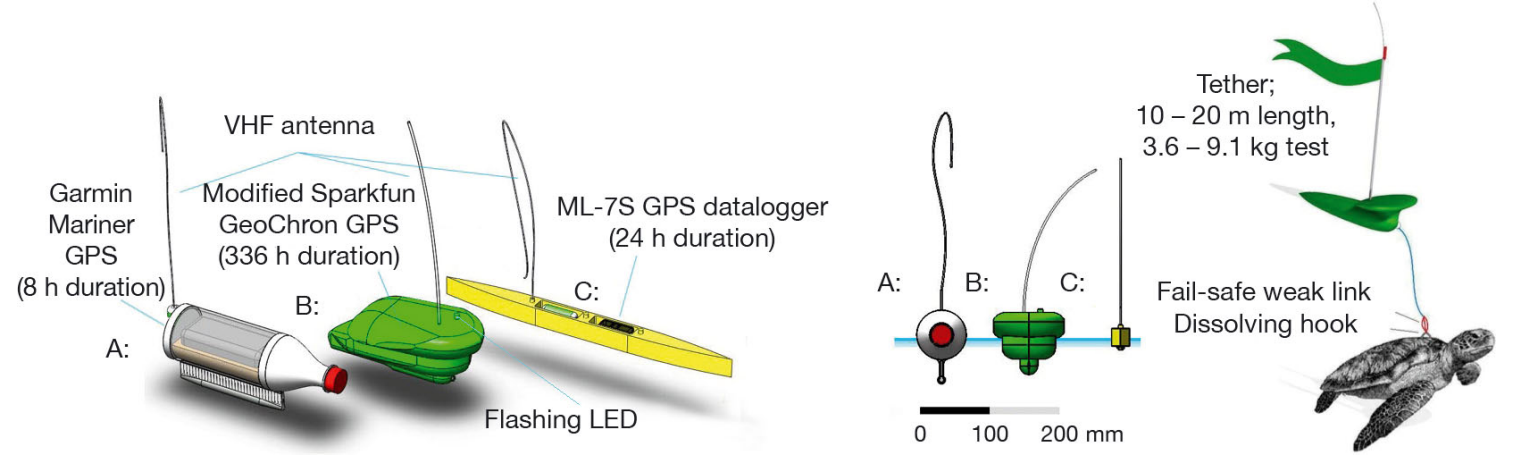

Fig. 1. Left: annotated diagram of each GPS-VHF tracking tag deployed during the course of this study; A: first iteration, B: second iteration, C: third iteration. The blue line in the frontal view indicates the average waterline of the fully laden tags. Right: schematic drawing of tethered GPS-VHF tag attached to turtle 
Table 1. Summary of tracking effort and device performance for green turtles tracked during the course of the study. First-, second-, and third-iteration tags were used for turtles tracked during 2003, 2008, and 2010, respectively. Track durations represent full tracks from deployment to termination. SCL: straight carapace length; NA: not available

\begin{tabular}{|lcccccc|}
\hline Turtle ID & $\begin{array}{c}\text { SCL } \\
(\mathrm{cm})\end{array}$ & $\begin{array}{c}\text { Mass } \\
(\mathrm{kg})\end{array}$ & $\begin{array}{c}\text { Tag:mass } \\
\text { ratio }\end{array}$ & $\begin{array}{c}\text { Tracking } \\
\text { interval }(\mathrm{mo} / \mathrm{d} / \mathrm{yr})\end{array}$ & $\begin{array}{c}\text { Tracking } \\
\text { duration }(\mathrm{h})\end{array}$ & $\begin{array}{c}\text { Reason for } \\
\text { termination }\end{array}$ \\
\hline CM A & 55.9 & 21.8 & 0.023 & $7 / 2 / 03-7 / 2 / 03$ & 5.2 & Natural break \\
CM B & 47.3 & 12.5 & 0.041 & $7 / 4 / 03-7 / 5 / 03$ & 25.5 & Natural break \\
CM C & 53.6 & 22.0 & 0.023 & $7 / 4 / 03-7 / 5 / 03$ & 18.7 & Terminated \\
CM D & 53.6 & 21.0 & 0.024 & $7 / 8 / 03-7 / 14 / 03$ & 51.3 & Terminated \\
CM E & 68.9 & NA & NA & $7 / 8 / 03-7 / 10 / 03$ & 28.3 & Natural break \\
CM F & 58.6 & 25.9 & 0.012 & $7 / 11 / 03-7 / 12 / 03$ & 12.0 & Natural break \\
CM G & 59.0 & 24.4 & 0.021 & $7 / 14 / 03-7 / 16 / 03$ & 53.0 & Natural break \\
CM H & 53.1 & 21.0 & 0.024 & $7 / 22 / 03-7 / 23 / 03$ & 8.7 & Terminated \\
CM I & 54.8 & 19.8 & 0.026 & $7 / 24 / 03-7 / 26 / 03$ & 38.5 & Natural break \\
CM J & 56.4 & 23.8 & 0.021 & $7 / 24 / 03-7 / 25 / 03$ & 22.0 & Natural break \\
CM K & 48.1 & 17.6 & 0.029 & $7 / 29 / 03-7 / 30 / 03$ & 20.7 & Natural break \\
CM L & 63.5 & 26.3 & 0.019 & $8 / 1 / 03-8 / 2 / 03$ & 21.3 & Terminated \\
CM M & 43.9 & 9.1 & 0.056 & $8 / 2 / 03-8 / 3 / 03$ & 16.5 & Natural break \\
CM 14 & 56.2 & 24.0 & 0.010 & $6 / 11 / 08-6 / 19 / 08$ & 184.0 & Natural break \\
CM 15 & 44.6 & 10.9 & 0.022 & $6 / 18 / 08-6 / 21 / 08$ & 86.0 & Natural break \\
CM 16 & 62.4 & 31.2 & 0.004 & $6 / 19 / 08-6 / 22 / 08$ & 75.5 & Natural break \\
CM 17 & 69.9 & 43.5 & 0.006 & $6 / 20 / 08-6 / 21 / 08$ & 41.5 & Natural break \\
CM 18 & 59.2 & 26.9 & 0.009 & $6 / 20 / 08-6 / 24 / 08$ & 98.5 & Natural break \\
CM 19 & 83.5 & 75.6 & 0.004 & $6 / 25 / 08-6 / 27 / 08$ & 56.1 & Natural break \\
CM 20 & 58.4 & 26.6 & 0.004 & $6 / 3 / 2010-6 / 5 / 2010$ & 24.7 & Natural break \\
CM 21 & 73.0 & 52.2 & 0.002 & $6 / 4 / 2010-6 / 5 / 2010$ & 28.1 & Natural break \\
CM 22 & 67.0 & 39.9 & 0.003 & $6 / 10 / 2010-6 / 12 / 2010$ & 24.4 & Natural break \\
CM 23 & 63.8 & 32.7 & 0.003 & $6 / 10 / 2010-6 / 13 / 2010$ & 51.2 & Terminated \\
CM 24 & 54.6 & 24.4 & 0.004 & $7 / 5 / 2010-7 / 7 / 2010$ & 15.4 & Natural break \\
CM 25 & 68.0 & 43.4 & 0.002 & $7 / 5 / 2010-7 / 7 / 2010$ & 42.1 & Terminated \\
CM 26 & 50.2 & 17.6 & 0.006 & $9 / 2 / 2010-9 / 6 / 2010$ & 72.9 & Terminated \\
& & & & & & \\
\hline
\end{tabular}

stainless steel rods were attached as ballast on the underside of the buoy to keep it upright and the VHF antenna out of the water. The GPS unit (model ML7S, San Jose Technology) was sealed in 2 rubber balloons to protect it from saltwater intrusion. The GPS units were configured to record the location every $5 \mathrm{~min}$ for up to $48 \mathrm{~h}$, and the device had a reported positional accuracy of $3.3 \mathrm{~m}$ by the manufacturer. VHF transmitters (model F1835B, ATS) were again fitted to the tags. Tracking devices were deployed on 7 free-living green turtles in 2010 at LSI, BCS (Table 1).

The reported positional accuracy of the GPS devices by the manufacturers ranged from 3.3 to $10 \mathrm{~m}$. When taking the 10 to $20 \mathrm{~m}$ tether into account, the total positional accuracy of our tags ranged from approximately 13.3 to $30 \mathrm{~m}$.

\subsection{Laboratory trials}

We used an instrumented open-top flow tunnel to measure the drag force induced by each of the 3 tag designs. The tunnel, whose working section measured $30 \mathrm{~cm}$ wide $\times 60 \mathrm{~cm}$ long, generated uniform flows at speeds up to approximately $0.8 \mathrm{~m} \mathrm{~s}^{-1}$ across all but the $5 \mathrm{~cm}$ boundary layer along the walls of the chamber. A cantilevered beam fitted with strain gauges was suspended into the flow at the upstream end of the working section. The drag force on the beam alone was then measured as a function of flow velocity.

Tags were tethered to the end of the beam using the same monofilament fishing line (approximate diameter of $0.3 \mathrm{~mm}$ ) that was used to track turtles in the field. The tags were then tested at increasing flow speeds up to approximately $0.8 \mathrm{~m} \mathrm{~s}^{-1}$, which were selected to span the range of green turtle swimming speeds observed in the wild following Senko et al. (2010b). Experiments were terminated when the motion of the tags in the flow became unstable. The drag force on the combined system was then measured as a function of flow velocity, and the drag on the tags was calculated by subtracting the drag force on the unloaded beam from the combined system drag.

\subsection{Relative drag calculations}

To determine the effect of the tags on movement patterns of free-living green turtles, we calculated the magnitude of the additional drag on the turtle due to the tag relative to the drag that would normally act on the animal's body. The drag or resistance $(R)$ on a submerged body (i.e. the turtle) moving at depth through a fluid is given by:

$$
R=\frac{1}{2} \rho A C_{D} u^{2}
$$

where $\rho$ is the density of the fluid (salt water: $\left.1030 \mathrm{~kg} \mathrm{~m}^{-3}\right) ; A$ is a representative surface area; $C_{D}$ is the drag coefficient referenced to that area, which accounts for shape, surface roughness, and the me- 
chanical properties of the fluid; and $u$ is the relative velocity of the body through the fluid (Biewener 2003).

Three previous studies (i.e. Prange 1976, Watson \& Granger 1998, Jones et al. 2013) reported values for the drag coefficient of green turtles, although they each used a different standard. Jones et al. (2013) and Watson \& Granger (1998) defined their drag coefficients relative to the projected frontal area. Prange (1976) defined his drag coefficient for a $0.27 \mathrm{~m}$ long juvenile green turtle based on a representative area equal to the square of the carapace length. He then fit a function to his data to obtain the expression $C_{D}=$ $0.09129 u^{0.219}$ (Prange 1976), where $u$ is again the forward velocity of the animal. While a nearly exact fit to his data, this expression does not lend itself well to extrapolation or comparison with drag on other submerged semi-streamlined bodies. We therefore fit our quadratic model (Eq. 1) to his data and calculated a drag coefficient, referenced to frontal area, for the juvenile green turtle data presented by Prange (1976) of $C_{D}=0.14$, which is nearly identical to the $C_{D}=0.13$ reported by Jones et al. (2013) for adult green turtles and one-third of that reported by Watson \& Granger (1998) for a juvenile. We assumed that for the range of Reynolds numbers being considered here $\left(10^{4}-10^{6}\right)$, the drag coefficient is essentially independent of velocity, which is consistent with most studies of flow over semi-streamlined bodies (Biewener 2003). Using the scaling relationship for frontal area $\left(\mathrm{FA}\right.$, in $\left.\mathrm{m}^{2}\right)$ to body length (BL, in $\mathrm{cm}$ ) FA $=5 \times 10^{-5} \times \mathrm{SCL}^{1.79}$ presented by Jones et al. (2013), we can calculate the overall drag on green turtles of all sizes swimming at realistic speeds observed in the field.

In tethered submersible engineering, the tether is sometimes more important than the drag on the vehicle (Christ \& Wernli 2007). Drag on the tether $\left(R_{\mathrm{t}}\right)$ is given by:

$$
R_{\mathrm{t}}=\frac{1}{2} \rho\left(\frac{d_{\mathrm{t}} L}{12}\right) C_{\mathrm{T}} u^{2}
$$

where $\rho$ is the density of the water; $d_{\mathrm{t}}$ is the diameter of the tether; $L$ is the length of the tether, which is perpendicular to the flow; $C_{\mathrm{T}}$ is the drag coefficient for a cylindrical line; and $u$ is the speed of the turtle relative to the water. The $C_{\mathrm{T}}$ for a cylindrical line is given by Christ \& Wernli (2007) as 1.2.

Drag on a surface vessel is the sum of the friction drag of the submerged part of the hull in the water and the wave-making resistance due to the interaction between the tag and the surface of the water (Hoerner 1993):

$$
R_{\mathrm{t}}=\frac{1}{2} \rho S_{\mathrm{w}} C_{D} u^{2}+b u^{4}
$$

where again $\rho$ is the density of the water; $S_{\mathrm{w}}$ and $C_{D}$ are the wetted surface area and drag coefficient, respectively, of the submerged part of the vessel; $u$ again is the velocity of the vessel through the water; and $b$ is the wave-making resistance coefficient.

\subsection{Field testing}

The first study site, where the 2003 (first tag iteration) turtles were tracked, was EB, a shallow system of tidal channels (total area 4200 ha) located on the Pacific coast of BCS in Bahia Magdalena (see Brooks et al. 2009 for map of study area). Algae and seagrass are patchily distributed, mangroves line most of the tidal waterways, water depth is generally 1 to $9 \mathrm{~m}$, and tidal currents average $0.29 \mathrm{~m} \mathrm{~s}^{-1}$ (Brooks et al. 2009).

The second study site, where the 2008 (second tag iteration) and 2010 (third tag iteration) turtles were tracked, was LSI, a shallow coastal lagoon (total area $\sim 17000$ ha) also located on the Pacific coast of BCS (see Senko et al. 2010b and Fig. 5 for map of study area). Tidal currents are strong, averaging $1 \mathrm{~m} \mathrm{~s}^{-1}$ in the lower lagoon (Winant \& Gutierrez de Velasco 2003), with tidal amplitudes sometimes exceeding $2 \mathrm{~m}$ at spring tides. In the upper lagoon, where most of our tracks were obtained, maximum tidal and winddriven flow speeds reach up to $0.45 \mathrm{~m} \mathrm{~s}^{-1}$ (Gutierrez de Velasco \& Winant 2004). Water depth is generally 1 to $9 \mathrm{~m}$, with large shallow water shoals, intertidal flats, and extensive mangrove swamps along the shoreline (Senko et al. 2010b). The substrate in the upper lagoon consists primarily of sand and mud (Kurth 2007), with abundant seagrass and algae beds (Kurth et al. 2008, Senko et al. 2010b).

Turtles were captured using an entanglement net (100 m long, 25 and $50 \mathrm{~cm}$ stretched mesh) set at slack tide. Upon capture, turtles were removed from the net and measured, weighed, and tagged in the rear flipper (Senko et al. 2010b). Marine turtles often contain epibionts, such as barnacles, that act as natural biofoulers which can increase drag (Logan \& Morreale 1993); therefore, we removed all epibionts from the carapace and plastron of turtles prior to attachment of tracking tags.

\subsection{Tethered carapace attachment}

Tracking tags were attached to turtles with a tether of positively buoyant monofilament fishing line (10$20 \mathrm{~m}$ length; $3.6-9.1 \mathrm{~kg}$ test). A length of 10 to $20 \mathrm{~m}$ was chosen because depth was usually $<10 \mathrm{~m}$ at both 
study sites, so that tagged turtles would not drag the tag under water resulting in a disruption to their natural buoyancy. The carapace attachment point was a steel paperclip glued to the middle of the turtle's second central scute using a small dab of 5 min quick-set epoxy. The scute was gently cleaned with sandpaper and alcohol for better adhesion prior to application of the epoxy. The paperclip was specifically not made of stainless steel, so that it would degrade over time. The location was selected as near as possible to the turtle's center of mass to minimize the potential yaw or pitch torques on the turtle due to the hydrodynamic drag on the tag.

The tether was attached to the turtle using a failsafe weak link that was comprised of 3 separate 2.7 to $4.5 \mathrm{~kg}$ monofilament test lines of differing lengths (10-12 cm for the first line; 6-8 cm for the second line; 3-5 $\mathrm{cm}$ for the third line) connected to a snap swivel. The design was implemented to facilitate the turtle's escape if the tag or tether snagged. The 3 loops were designed to stretch to the same length when pulled taught, thereby acting in parallel to achieve the same strength as the overall tether, but the series design ensured that the breakage during a high-force event would occur near the attachment rather than at an unpredictable location along the tether. The intent was also to minimize impact on the animal once a tracking episode had ended.

\subsection{Turtle tracking}

We observed the location, behavior, and condition of the turtle and the tag at both study sites using binoculars and a 3-element Yagi VHF antenna and receiver (model R410, ATS). Positions were triangulated from shore using up to 10 stations placed $1 \mathrm{~km}$ apart, approximately every 2 to $6 \mathrm{~h}$ to maintain contact with turtles. We were able to triangulate positions from shore at all times because the turtles remained in the study area while being tracked. We used fiberglass skiffs that were approximately 5.5 to $6 \mathrm{~m}$ in length to observe the location and condition of the turtle and the tag twice per day using VHF and binoculars from a distance of $>100 \mathrm{~m}$ so as to not affect the behavior of the animal. Tags were replaced when the voltage levels in the batteries became low. We made these replacements based on how long the batteries maintained a charge during pre-tracking trials. Tracking was terminated when the tether either broke naturally or was removed from the turtle with a gentle pull (Table 1). All natural breaks occurred at the weak link, meaning that the vast majority of the tether was retrieved from the environment and not left trailing the turtle.

\subsection{Data processing and analysis}

Data were downloaded from the GPS units to a laptop. Tracks were extracted from time-stamped latitude and longitude records using the Points2One plugin (v. 1.0.2) in QGIS (v. 2.10.1). The resulting shapefiles from 2008 and 2010 were edited following Senko et al. (2010b), which included removing the first $6 \mathrm{~h}$ of post-release tracking data to account for behavioral responses to capture, and compiled in ArcMap (v. 10.4). The basemap was extracted from LandsatLook Viewer. Extracted tracks from 2008 and 2010 were further smoothed using a third-order complex Savtizky-Golay filter (Press et al. 2007) with a 6-point sampling window to reduce the noise in the tracks due to the inherent imprecision of the GPS system.

Our underwater video observations (authors' unpubl. data) of the turtles' behavior in LSI when tagged indicated that they move mostly forward but take left and right turns as they forage. To quantify such movements, the most appropriate (Almeida et al. 2010) parameters to measure are the path sinuosity, SI (Bovet \& Benhamou 1988), and fractal dimension, $D$ (Nams 2013).

Path sinuosity (Bovet \& Benhamou 1988) is a measure of tortuosity that assumes the movement to be a correlated random walk and relates the step length between turns with the magnitude of the turn angle, as shown in Eq. (4).

$$
S I=2\left[p\left(\frac{1-c^{2}-s^{2}}{(1-c)^{2}+s^{2}}+a^{2}\right)\right]^{-0.5}
$$

where $p$ is the mean step length, $c$ is the mean cosine of turning angles, $s$ is the mean sine of turning angles, and $a$ is the coefficient of variation of step length. Step length was defined as the straight-line distance (i.e. net displacement) between 2 GPS fixes (Senko et al. 2010b) and thus varied with swimming speed since the GPS sampling rate was constant. Sinuosity describes the shape of the path using a measure of the magnitude of course changes made by the animal. Essentially, it describes the animal's relative course changes or its decision to turn left or right as it swims.

By contrast, fractal $D$ represents the amount of the 2-dimensional space explored by the animal. The parameter is intuitively a measure of the dimensionality of the area coverage: a value of 1 indicates an 
animal swimming back and forth along a nearly straight line, whereas a value of 2 indicates complete 2 -dimensional coverage of the area (an animal that visited the entire habitat). Intermediate values represent incomplete coverage due to path constraints. We calculated the fractal $D$ (Nams 2006) using the computer program FRACTAL (Nams 2013).

We calculated a body condition index $(\mathrm{BCI}=$ body mass $\times 10000 \mathrm{SCL}^{-3}$ ) to compare relative fatness of turtles tracked in 2008 and 2010 following Bjorndal et al. (2000). We used $t$-tests to compare speed, tracking duration, $\mathrm{SCL}$, and BCI of turtles tracked between 2008 and 2010 and a Mann-Whitney $U$-test to compare tortuosity and sinuosity of turtles tracked between 2008 and 2010.

\section{RESULTS}

\subsection{Laboratory trials}

The maximum test speed for the first tag was $0.843 \mathrm{~m} \mathrm{~s}^{-1}$ with a maximum horizontal drag force of $1.32 \mathrm{~N}$ (Fig. 2). The maximum test speed for the second tag was $0.545 \mathrm{~m} \mathrm{~s}^{-1}$ with a maximum horizontal drag force of $0.45 \mathrm{~N}$, while the maximum test speed for the third tag was $0.76 \mathrm{~m} \mathrm{~s}^{-1}$ with a maximum horizontal drag force of $0.09 \mathrm{~N}$ (Fig. 2). The first 2 tag

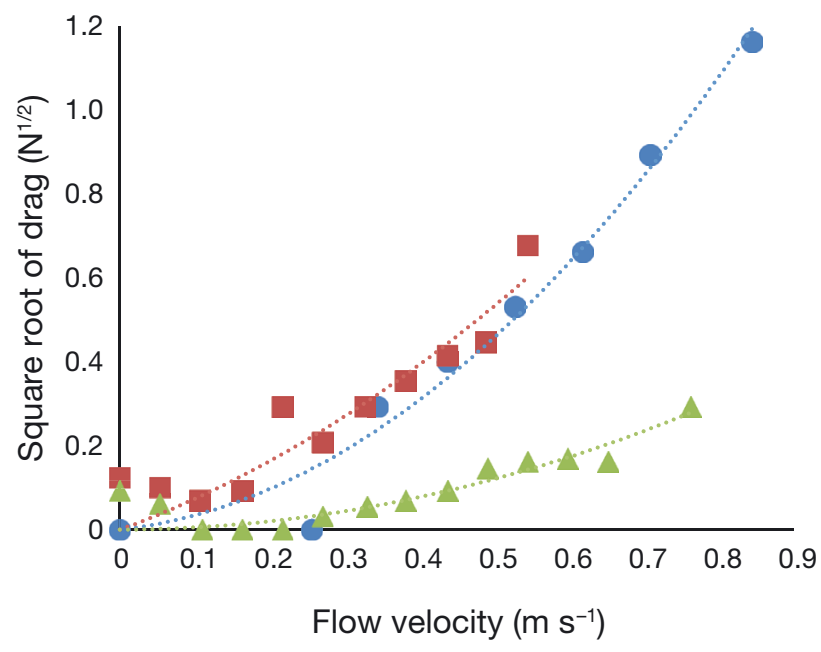

Fig. 2. Total drag force $(\mathrm{N})$ experienced by the 3 tag designs at increasing current speeds in a flow tunnel. Total drag force is the sum of the form and friction drag $\left(\alpha v^{2}\right)$ and the wavemaking resistance $\left(\alpha v^{4}\right)$. The vertical axis is shown as the square root of drag to improve the resolution of the graph at the lower velocities. Tags 1 (blue circles) and 2 (red squares) are virtually indistinguishable, whereas tag 3 (green triangles) demonstrates a clear improvement. The parabolic shape of the curves on this plot highlights the dominance of the wave-making resistance in the overall drag force designs were indistinguishable despite their very different geometries, whereas the third tag was a substantial improvement.

If the assumption of geometric scaling of carapace dimension can be accepted (and thus the drag coefficient remains unchanged with dimension), then the drag on a sub-adult green turtle of typical carapace length $0.7 \mathrm{~m}$ (Senko et al. 2010b) swimming at the speeds observed here $\left(0.3 \mathrm{~m} \mathrm{~s}^{-1}\right)$ would be approximately 0.65 to $1.2 \mathrm{~N}$, depending on the choice of drag coefficient $\left(C_{D}=0.14\right.$ [Prange 1976, Jones et al. 2013] or $C_{D}=0.38$ [Watson \& Granger 1998]).

The parabolic shape of the drag curves in Fig. 2 shows that the drag on the tags is a fourth-order function of velocity, consistent with the theory of friction and wave-making resistance by surface vessels (Hoerner 1993), and that it is clearly the wave-making resistance which dominates in all designs. The functional fits to the data make it possible to infer the magnitude of the drag for all swim speeds.

Turtles were usually observed in depths of $5 \mathrm{~m}$ or less (Senko et al. 2010b). As previously noted (Section $2.3)$, the drag coefficient for a cylindrical line is 1.2 (Christ \& Wernli 2007). The estimate of drag on the tether for a typical turtle swimming at $0.3 \mathrm{~m} \mathrm{~s}^{-1}$ is $R=$ $1 / 2 \times 1030 \times 0.000125 \times 1.2 \times 0.3^{2}=0.007 \mathrm{~N}$. Thus, the tether drag is negligible compared to that of tags 1 and 2, but at low speeds it is of comparable magnitude to that of the kayak-shaped tag 3 and thus must be considered when calculating the overall drag incurred by the turtle.

\subsection{Relative drag increase}

The ratio of the drag on the tag and tether system to that on the turtle is dependent on the size of the turtle and its swimming speed (Fig. 3). Except for the smallest turtles, at a typical speed of $1 \mathrm{BL} \mathrm{s}^{-1}$ (Prange 1976), drag on the early tag designs effectively doubles the total drag on the turtle. The latest design reduces this considerably, accounting for an increase generally of approximately $5 \%$, and even for the smallest turtles, an increase of only $9 \%$ (Fig. 3). Data in the figure are limited to less than $2 \mathrm{BL} \mathrm{s}^{-1}$, as this is known to be the limit speed which immature-sized turtles can maintain without being tagged (Butler et al. 1984). The curves in the figure are all calculated using the $C_{D}=0.14$ value reported by Prange (1976) and Jones et al. (2013). If the Watson \& Granger (1998) value is used, then the drag on the turtle is increased by a factor of 3 , and the impact of the tag system on the overall drag is comparatively reduced. 


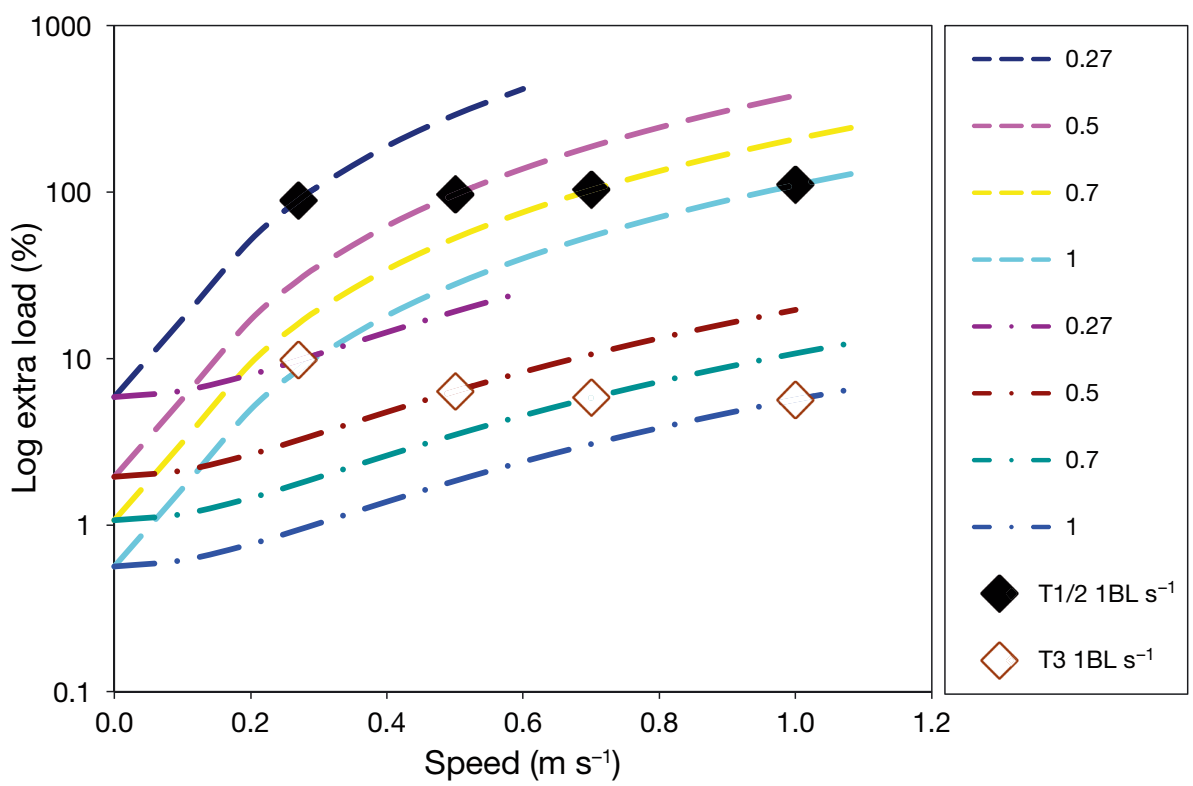

Fig. 3. Drag of the tags and tethers as a proportion of hydrodynamic drag on the shells of green turtles at the range of swimming speeds observed in the field. Vertical axis is shown as a log scale to highlight the differences. Dashed lines and solid symbols correspond to tags 1 and 2 (T1/2), while dot-dashed lines and open symbols refer to tag 3 (T3). Legend numbers are carapace lengths in meters. Traces for the smaller turtles are stopped at 2 body lengths $\mathrm{s}^{-1}$, well beyond the maximum observed swimming speeds for animals of this size during the field component of this study. T: tag; BL: body length

Table 1). The tags provided finescale tracks that ranged from 5.2 to $184.0 \mathrm{~h}$, totaling $1122 \mathrm{~h}(43.2 \pm$ $37.8 \mathrm{~h}$; Table 1). The tag:turtle mass ratio ranged from 0.1 to $5.6 \%$, although it ranged from 0.1 to $2.2 \%$ for the latter 2 (2008 and 2010) tag iterations (Table 1). Of the 26 tracking events, 19 (73\%) ended because the tether broke naturally during tracking, resulting in decreased tracking durations for those tracks, while the remaining 7 (27\%) were terminated manually with a gentle pull of the tether (Table 1).

All tags were successfully recovered at the termination of tracking; all tags remained intact, all GPS units and VHF transmitters remained in the same position within the tag, and we did not observe the tags being dragged underwater by the turtles. The low-drag kayak-shaped (2010) tags tended to roll considerably,

When analyzing the entire tag system (including the effect of the tether), it is clear from Fig. 2 that the earlier tag designs incurred higher drag than the third design. The fourth-order dependence of the wavemaking resistance on the velocity means that the contribution to the overall drag by the surface tag increases substantially with velocity. At higher speeds, the additional drag due to the early tag designs represents an approximate doubling of the drag, whereas for the latest design, the additional drag is $9 \%$ of the drag that the turtle would experience simply due to its own motion in the water. In this study, tags were applied almost entirely to larger juveniles, generally of carapace length $>45 \mathrm{~cm}$ (Brooks et al. 2009, Senko et al. $2010 \mathrm{~b}$; see Table 1). Typical swimming speeds were also much slower, with means of 0.1 to $0.3 \mathrm{~m} \mathrm{~s}^{-1}$ (Brooks et al. 2009, Senko et al. 2010b). At these sizes and speeds, we calculate that the animals were experiencing additional drag of approximately 7 to $10 \%$ with the first- and second-generation tags and $1 \%$ or less with the third-generation kayak-shaped tag.

\subsection{Turtle tracking and movement patterns}

We tracked 26 green turtles that ranged in size from 43.9 to $83.5 \mathrm{~cm}$ SCL (mean $\pm \mathrm{SD}=58.8 \pm 9.2$; while the higher-drag tags (2003 and 2008) were more roll stable. The total cost of each tracking iteration (4 tags in each) at the time of respective development was 690 USD (2003), 735 USD (2008), and 728 USD (2010), with a total equipment cost of 1025 USD for tracking the tags and recovering the data (Table 2), although this does not account for tracking effort costs (e.g. boat, fuel, labor).

In 2003, with the first-generation tags, we tracked 13 turtles for periods of 5.2 to $56.6 \mathrm{~h}$ (mean $\pm \mathrm{SD}=$ $24.7 \pm 14.9 \mathrm{~h}$ ), with travel speeds of 0.028 to $1.41 \mathrm{~m} \mathrm{~s}^{-1}$ $\left(0.24 \pm 0.14 \mathrm{~m} \mathrm{~s}^{-1}\right)$ (Brooks et al. 2009). In 2008, using the second-generation tags, we tracked 6 turtles from 41.5 to $184 \mathrm{~h}(90.3 \pm 50.3 \mathrm{~h})$, with travel speeds of 0.027 to $0.33 \mathrm{~m} \mathrm{~s}^{-1}\left(0.15 \pm 0.05 \mathrm{~m} \mathrm{~s}^{-1}\right.$ ) (Senko et al. 2010 b). In 2010, with the third-generation kayakshaped tags, we tracked 7 turtles for periods of 15.4 to $72.9 \mathrm{~h}(37.0 \pm 19.9 \mathrm{~h})$, with travel speeds of 0.08 to $0.21 \mathrm{~m} \mathrm{~s}^{-1}\left(0.15 \pm 0.04 \mathrm{~m} \mathrm{~s}^{-1}\right)$.

There were no significant differences in BCI or SCL between turtles tracked with the high-drag tags in 2008 (mean $\pm \mathrm{SD}: \mathrm{BCI}=1.289 \pm 0.040 ; \mathrm{SCL}=62.6$ $\pm 13.2 \mathrm{~cm})$ and those tracked with the low-drag tags in $2010(\mathrm{BCI}=1.362 \pm 0.074, \mathrm{p}=0.055 ; \mathrm{SCL}=62.1 \pm$ $8.1 \mathrm{~cm}, \mathrm{p}=0.809$ ), although tracking durations were significantly longer in 2008 than in 2010 ( $p=0.025)$. Although turtle speeds were consistent between the 
Table 2. Estimated costs associated with our tracking devices at the respective time of tag development. The total cost of each device $(2003,2008,2010)$ includes 4 separate tags. Costs are indicative of market prices for the time of each tag design. NA: not applicable; NiMH: nickel-metal hydride; Li-Po: lithium polymer

\begin{tabular}{|c|c|c|c|}
\hline Tracking component & Specifications & Quantity & Total cost (USD) \\
\hline \multicolumn{4}{|l|}{ Equipment } \\
\hline VHF receiver & ATS & 1 & 810 \\
\hline Yagi antenna & ATS 3 pole & 1 & 150 \\
\hline Line (tether) & Monofilament fishing line & $2743 \mathrm{~m}$ & 30 \\
\hline Attachment material & 5 min quick-set epoxy & 4 & 20 \\
\hline Other & Foam, flags, steel, tape & NA & $\begin{array}{l}15 \\
1025 \text { total }\end{array}$ \\
\hline \multicolumn{4}{|l|}{ First tag design } \\
\hline GPS logger & Garmin eTrex Mariner & 4 & 400 \\
\hline VHF transmitters & ATS F1800 & 4 & 240 \\
\hline Battery & AAA NiMH rechargeable & 16 & 50 \\
\hline Buoy & Recycled soda bottle & 4 & $\begin{array}{l}0 \\
690 \text { total }\left(172.50 \operatorname{tag}^{-1}\right)\end{array}$ \\
\hline \multicolumn{4}{|l|}{ Second tag design } \\
\hline GPS logger & SparkFun Electronics EM-408 & 4 & 250 \\
\hline VHF transmitters & ATS F1800 & 4 & 240 \\
\hline Battery & 8000 mAh Li-Po rechargeable & 8 & 125 \\
\hline Buoy & Resin-reinforced balsa wood & Block for 4 buoys & 50 \\
\hline Vacuum sealer & FoodSaver ${ }^{\circledR}$ & 1 & 50 \\
\hline Protective packaging & Ziploc $^{\circledR}$ vacuum bags & 2 packages & $\begin{array}{l}20 \\
735 \text { total }\left(183.75 \operatorname{tag}^{-1}\right)\end{array}$ \\
\hline \multicolumn{4}{|l|}{ Third tag design } \\
\hline GPS logger & Sanav ML-7 & 4 & 308 \\
\hline VHF transmitters & ATS F1800 & 4 & 240 \\
\hline Battery & 8000 mAh Li-Po rechargeable & 8 & 125 \\
\hline Buoy & Resin-reinforced balsa wood & Block for 4 buoys & 50 \\
\hline Protective packaging & Rubber balloons & 1 package & $\begin{array}{l}5 \\
728 \text { total }\left(182 \operatorname{tag}^{-1}\right)\end{array}$ \\
\hline
\end{tabular}

high- (2008) and low-drag (2010) tags ( $p=0.834)$, both sinuosity and fractal $D$ were different (Fig. 4). Sinuosity, which measures the changes in direction, was significantly lower in $2008(0.085 \pm 0.033)$ than in $2010(0.172 \pm 0.040, \mathrm{p}=0.005 ;$ Fig. 4). Fractal $D$, which measures how much area is covered by the track, was also significantly lower for turtles tracked with the high-drag tag $(1.065 \pm 0.016)$ compared with the low-drag tag $(1.170 \pm 0.043, \mathrm{p}<0.005$; Fig. 4)

\section{DISCUSSION}

We report here on the development and assessment of a low-cost tethered telemetry system $(<185$ USD $\operatorname{tag}^{-1}$ ) for short-term, fine-scale tracking of marine turtles in nearshore environments. The telemetry system consisted of 3 different tag designs that each incorporated a standard GPS data logger and VHF transmitter that were stored in custom-made buoyant housings and attached to turtles with a fail-safe release tether. Each subsequent design iteration reduced the hydrodynamic drag of the tag and hence the resistance felt by the turtle towing it. In the field, the high-drag tags corresponded to turtles making fewer course changes and straighter (less tortuous) movements compared with the lowest-drag tag.

\subsection{Design iterations and hydrodynamic drag reduction}

Laboratory experiments revealed that the 3 tag iterations produced markedly different hydrodynamic drag forces. The wave-making resistance generated by the tag hulls was the largest component of the overall drag force on all designs, with the drag on the tether becoming relatively important in the final, most streamlined iteration. At the highest swimming speeds observed, the streamlining improvements reduced the drag felt by the turtle from nearly double its untagged state to an increase of only $9 \%$ in the final iteration. At the more typical turtle swimming speeds, the reduction was smaller but still important, improving from approximately $10 \%$ with the earliest iteration down to $1 \%$ or less with the final one. 


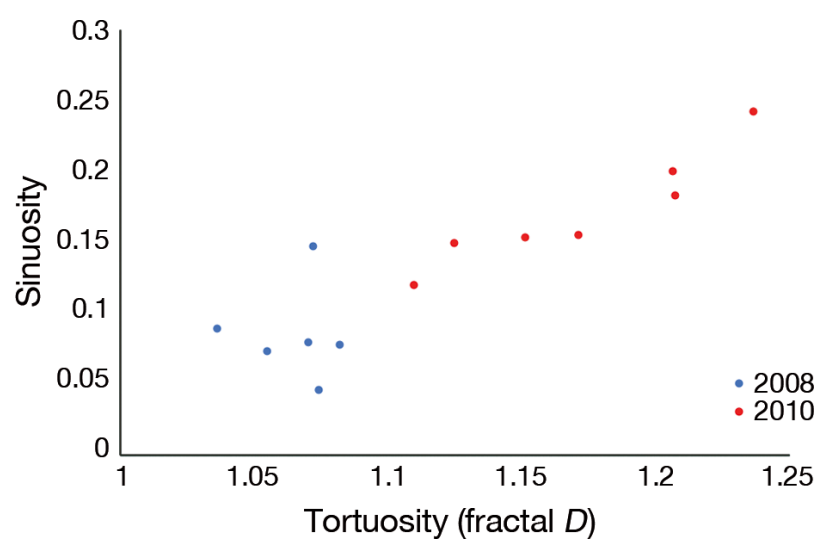

Fig. 4. Two-dimensionality of turtle tracks from the 2nd and 3rd-iteration tags. Each point represents the path followed by an individual turtle. Sinuosity depicts the shape of the path using a measure of the magnitude of course changes made by the animal. Tortuosity (fractal dimension, $D$ ) measures the amount of space within the habitat occupied by the animal, where a value of 1 is indicative of an animal swimming back and forth along a straight line, while a value of 2 represents complete 2-dimensional coverage of the area. Both sinuosity and fractal $D$ were significantly lower in 2008

\subsection{Effects of high- and low-drag tags on turtle movement patterns and behavior}

The lower fractal $D$ and sinuosity for turtles tracked with the high-drag tag indicate that the animals were turning less frequently and moving along a nearly linear path throughout the lagoon. Inspection of the mapped tracks in Fig. 5 demonstrates that the path is oriented parallel to the direction to the tidal flow, suggesting that turtles tracked with the heavier and less streamlined tags may have moved more linearly up and down the lagoon with the tidal currents. In large seagrass meadows with limited navigational landmarks, gentle tugging by the tags may not be enough to influence their decision making with respect to turning. However, it is also possible that turtles fitted with the high-drag tag may not have noticed the tugging from their tags and could have foraged on seagrass patches while swimming linearly up and down the lagoon with the tidal currents.

Movement analyses from the first tag design at EB revealed that immature green turtles moved with the tidal currents, which transported them continuously throughout the tidal cycle (Brooks et al. 2009). LSI, where turtles were tracked with the high- and lowdrag tags, is comprised of narrow channels with strong tidal currents (Winant \& Gutierrez de Velasco 2003, Gutierrez de Velasco \& Winant 2004). Although we were unable to measure tidal velocity, the benthic topography did not change significantly between the 2 testing years, nor did the lunar-driven cycling in the Pacific.

Although we have no data on food availability from either tracking year, to our knowledge there were no algal blooms, meteorological events, changes in the lagoon profile, or other discernable differences in environmental conditions between the 2 years. Still, we cannot exclude the possibility that the different movement patterns may have been a result of patch dynamics (Stephens \& Krebs 1987, Kotliar \& Wiens 1990, Zollner \& Lima 1999) as well as other oceanographic conditions. According to optimal search strategy, animals searching over long distances should move in nearly straight lines (Zollner \& Lima 1999). If the tags were dragging turtles off the center of their seagrass patch and near the edge where food availability would diminish, this could have influenced their decision to leave for another patch, especially since they would mistakenly assume that resource density was dropping. However, we cannot rule out the possibility that if seagrass patches were more dispersed when animals were tracked with the high-drag tags, their more linear movements could explain their search behavior in pursuit of new seagrass patches. By contrast, if seagrass patches were more condensed when animals were tracked with the low-drag tags, they would be expected to slow down and exploit it, which could explain the narrow distribution of all tracked turtles over areas of known seagrass in 2010.

Different predation pressures between years could have also influenced turtle movement decisions, as the presence of large sharks is known to affect microhabitat selection of green turtles in a conditiondependent manner (i.e. turtles in poor body condition select more profitable, high-risk microhabitats, whereas turtles in good condition select safer, less profitable microhabitats; Heithaus et al. 2007). Optimal search strategy suggests that animals will move straighter when they face greater mortality risk (Zollner \& Lima 1999). Although we have no data on shark abundance, small longline fisheries occasionally target requiem shark species (e.g. bull, tiger) inside the lagoon (Senko et al. 2010b). To our knowledge, however, no such fisheries were operating during either of the tracking periods, although this does not necessarily indicate the absence of large sharks capable of preying on turtles.

Optimal search strategy also implies that dispersing animals with limited energy reserves should move in straighter paths than those with greater energy reserves (Zollner \& Lima 1999). Although turtles tracked in 2010 were marginally (but not significantly) 

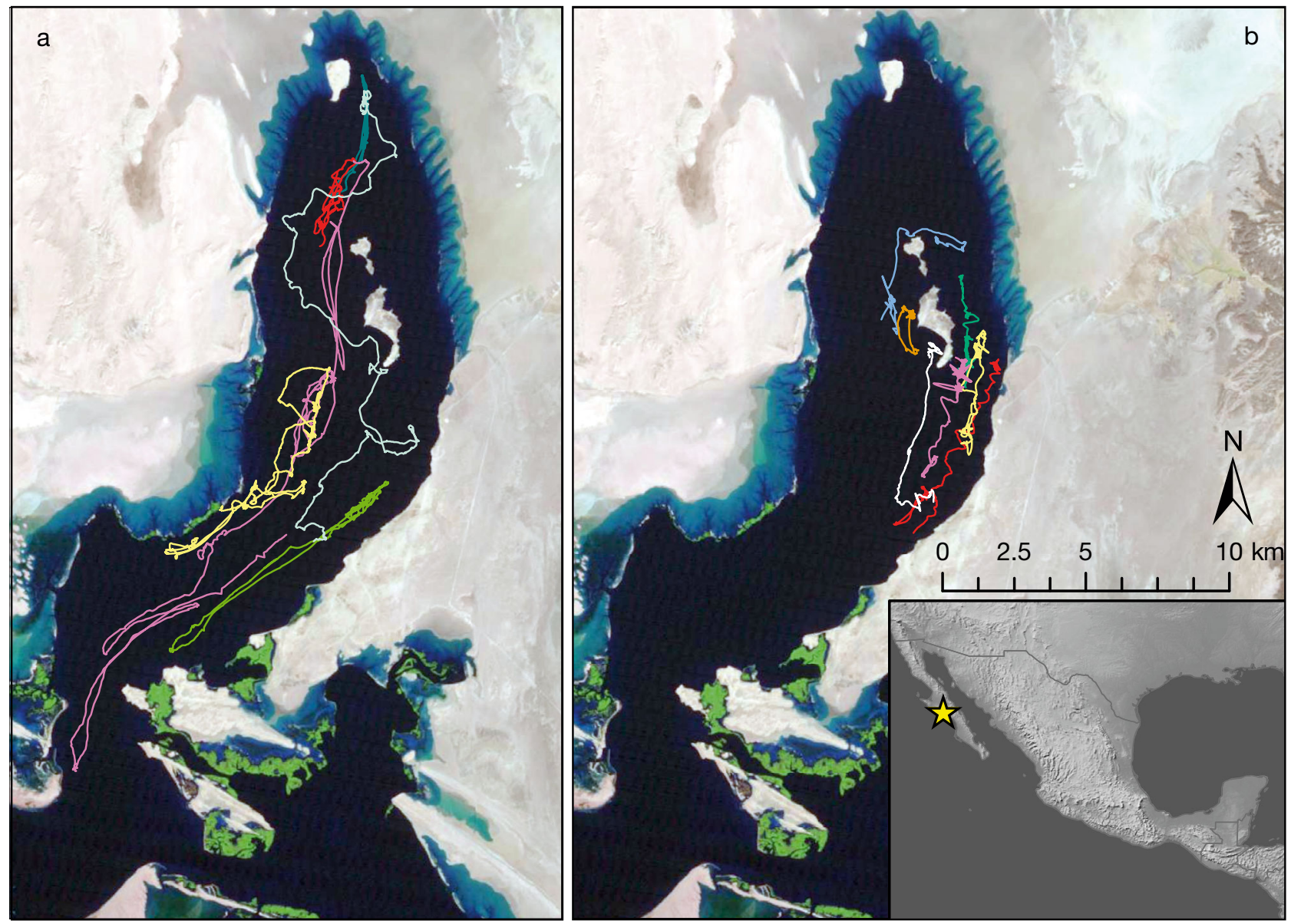

Fig. 5. Movement patterns of green turtles tracked in (a) 2008 with the high-drag tags and (b) 2010 with the low-drag tags at Laguna San Ignacio, Baja California Sur, Mexico (yellow star in inset; see Senko et al. 2010b for detailed map of study area). Turtles fitted with the low-drag 2010 tags exhibited more tortuous (less straight) movements and made more course changes than those fitted with the high-drag 2008 tags

fatter than those tracked in 2008, their BCI was considered healthy for both years (López-Castro et al. 2010), and external examination of all turtles indicated no apparent health problems (e.g. fibropapillomatosis) or physical injuries (e.g. vessel strikes, wounds, fishery interactions).

In addition to potential effects of drag, some deployments where tag loads exceeded $3 \%$ of the animal's mass have resulted in increased energy expenditure (Phillips et al. 2003, Casper 2009, Vandenabeele et al. 2012). However, tag:turtle mass ratios for the high- and low-drag tags ranged from 0.1 to $2.2 \%$ and only exceeded $1 \%$ in 2 of the 13 turtles tracked; thus, effects on locomotion were unlikely. Finally, movement patterns and GIS animations of tracks revealed that turtles resumed apparent normal behavior in less than 3 h (Senko et al. 2010b), suggesting that the observed behavioral differences were unlikely an artifact of tracking duration.

\subsection{Tag development and future design improvements}

Our tags were developed through a process of iterative prototyping, incorporating input and experience gained in the field from both engineers and biologists that translated into the improvement of each successive design (Dow et al. 2009). Although our most recent and lowest-drag tag was tested in 2010, GPS technology itself has changed little since then, demonstrating the feasibility of our low-cost tracking method to be modified for use today. The first tag was simply assembled from materials at hand and served as the starting point for technology development. It proved that while the concept was sound, its size, fragility, and short battery life limited its usefulness. The second tag was a more robust device with much improved battery life. However, its hydrodynamic performance was not better than the original design. 
The third iteration solved both problems: the miniature, energy-efficient GPS devices and improved battery technology made it possible to reduce the size of the float and thus the drag exerted on the turtle. The result was a design particularly well suited for shallow and protected nearshore environments. Although our short tracking durations should be interpreted with care, results from long-term tracking of green turtles at BCS suggest that $24 \mathrm{~h}$ movements can be a good indicator of long-term spatial use (Seminoff \& Jones 2006).

Prior to our study, extensive tagging and recapture data spanning a decade established that green turtles exhibit restricted spatial use at our 2 field sites, both of which were relatively small, shallow, and easy to access (Koch et al. 2007, López-Castro et al. 2010, Senko et al. 2010a.). Similar data on spatial use of other aquatic megafauna will help inform whether this tracking method is appropriate in other systems. Although our system was developed for marine turtles, the tracking technique can be modified for other aquatic megafauna that inhabit nearshore, shallowwater habitats, such as crocodilians and large-bodied $(>30 \mathrm{~cm}$ ) freshwater turtles, many of which are threatened or endangered. Future research could also be done on the forces generated by waves hitting the tag. Both the tugging force potentially generated and the potential shock-absorbing effect due to the curve of the trailing tether could be studied.

Further iterations would be required to overcome the challenges posed by locations with different habitat configurations. Habitats with extensive structure, such as coral reefs or mangrove swamps, would be especially challenging given the likelihood of frequent snagging. In open waters that are less prone to snags, it will be necessary to consider the transmission power of the VHF unit more carefully, and a more stable hull design might be required to keep the antenna more upright. These kinds of challenges are not always predictable at design time and are best overcome by maintaining the design flexibility offered by the iterative prototyping approach.

The type and length of the tether will be important considerations in the deployment of similar tags in other areas. A stronger weak link may increase tracking durations by reducing premature breaks, but researchers should be confident that instrumented animals will not become entangled, either directly by the tether during tracking or, upon breaking, by trailing a broken tether. Depending on the depth regime, a shorter tether would improve the spatial accuracy and reduce the propensity of the tether to snag or gather surface debris. Prior research has found that short tethers can be successfully used to track fine- scale movements of green turtles in similar areas where turtles only surface for brief intervals (Hazel 2009). However, shorter tethers would create a greater vertical component of tension in the line when pulled by the swimming animal, which might cause the device to submarine and lose satellite reception and potentially further influence the animal's behavior by inhibiting its ability to dive.

Contemporary GPS data loggers with longer-lasting batteries would reduce the need to exchange the tag during tracking and provide data over a longer temporal period. Hallworth \& Mara (2015) used miniaturized archival GPS technology (Pinpoint-10 archival GPS tag, Lotek Wireless) that weighed approximately $1 \mathrm{~g}$ to track small songbirds weighing $<20 \mathrm{~g}$. Similarly, Kennedy et al. (2015) used small, commercially available GPS loggers (20-channel receiver, Mobile Action Technology) with integrated data storage to characterize the movement patterns of free-ranging endangered parrots. As in our study, the loggers were removed from their original plastic housing and sealed to make them weatherproof (Kennedy et al. 2015). These data loggers were also inexpensive (70 USD each) and small enough $(\sim 60 \times 27 \times 12 \mathrm{~mm} ; 19 \mathrm{~g})$ to be configured to fit in our third tag design.

\subsection{Conservation implications}

Understanding impacts of telemetry devices on instrumented animals is important for animal welfare and elucidating representative behavior of tagged individuals. Although we are unable to definitively determine if the movement patterns we observed are due solely to the effects of the different tag designs, laboratory and field results suggest that substantially different drag imposed on juvenile turtles may have influenced their movement patterns. Regardless, our study underscores the need to assess and mitigate potential ecological effects of telemetry devices on instrumented animals. Increased drag can lead to increases in energy expenditure and elevated stress hormones, decreases in body condition, and reduced reproductive investment (Barron et al. 2010, Elliott et al. 2012, van der Hoop et al. 2017). We recommend continued efforts to develop low-drag devices that minimize effects on host species, such as our third tag design.

Acknowledgements. Fieldwork for this study was funded by a grant from the Earthwatch Institute, the National Fish and Wildlife Foundation, the Homeland Foundation, the Lerner Gray Foundation, Myers Oceanographic Trust, the PADI Foundation, the Laguna San Ignacio Wetlands Ecosystem 
Science Project, and Moss Landing Marine Laboratories at San Jose State University (SJSU). Field data were collected while J.F.S. and L.B.B. were students at the University of Florida and SJSU, respectively. We thank Taylor Wamberg for his help with flow tank trials. Fred Senko, Agnese Mancini, Susanne Megill, Amee Lewis, Rianna Burnham, Wallace J. Nichols, ProPeninsula, and the staff at Kuyima Ecotourism Camp provided logistical, management, and field support. Fred Senko provided invaluable engineering guidance, and Jackie Maud introduced us to path tortuosity. We thank all volunteers from the Earthwatch expedition 'Tracking Baja's Black Sea Turtles', Ranulfo Mayoral, Rodrigo Rangel, Julio Solis, Grupo Tortuguero, and the School for Field Studies students and staff for their invaluable field assistance. All research activities were authorized by the Secretaría para el Medio Ambiente y los Recursos Naturales (SEMARNAT) (permit nos. 280499.213.03 1565, 280700.213. 03 2619, SGPA/DGVS/06840/07，SGPA/DGVS/09142/07, SGPA/DGVS/01395/10), the SJSU Animal Care and Use Committee (IACUC no. 805), and the University of Florida Institute of Food and Agricultural Sciences Animal Research Committee (permit no. 017-09WEC). The Landsat image we used was courtesy of the US Geological Survey, and we thank Maxwell Wilson for help with map making. Fred Senko, Maxwell Wilson, Ray Carthy, and 2 anonymous reviewers provided helpful comments and suggestions that greatly improved the final manuscript.

\section{LITERATURE CITED}

Almeida PJAL, Vieira M, Kajin M, Forero-Medina G, Cerqueira R (2010) Indices of movement behavior: conceptual background, effects of scale and location errors. Zoologia 27:674-680

Barron DG, Brawn JD, Weatherhead PJ (2010) Meta-analysis of transmitter effects on avian behaviour and ecology. Methods Ecol Evol 1:180-187

Biewener AA (2003) Animal locomotion. Oxford University Press, New York, NY

Bjorndal KA, Bolten AB, Chaloupka MY (2000) Green turtle somatic growth model: evidence for density dependence. Ecol Appl 10:269-282

Bovet P, Benhamou S (1988) Spatial analysis of animals' movements using a correlated random walk model. J Theor Biol 131:419-433

Brooks LB, Harvey JT, Nichols WJ (2009) Tidal movements of East Pacific green turtle Chelonia mydas at a foraging area in Baja California Sur, México. Mar Ecol Prog Ser 386:263-274

* Butler PJ, Milsom WK, Woakes AJ (1984) Respiratory, cardiovascular and metabolic adjustments during steady state swimming in the green turtle, Chelonia mydas. J Comp Physiol B 154:167-174

Byrne R, Fish J, Doyle TK, Houghton JDR (2009) Tracking leatherback turtles (Dermochelys coriacea) during consecutive inter-nesting intervals: further support for direct transmitter attachment. J Exp Mar Biol Ecol 377:68-75

Casper RM (2009) Guidelines for the instrumentation of wild birds and mammals. Anim Behav 78:1477-1483

Christ RD, Wernli RL (2007) The ROV manual: a user guide to observation-class remotely operated vehicles. Elsevier, Oxford

Costa DP, Robinson PW, Arnould JPY, Harrison AL and others (2010) Accuracy of ARGOS locations of pinnipeds atsea estimated using Fastloc GPS. PLOS ONE 5:e8677
Denkinger J, Parra M, Muñoz JP, Carrasco C and others (2013) Are vessel strikes a threat to sea turtles in the Galapagos Marine Reserve? Ocean Coast Manage 80:29-35

* Dow SP, Heddleston K, Klemmer SR (2009) The efficacy of prototyping under time constraints. Proc 7th ACM Conf on Creativity and Cognition 2009:165-174

* Dujon AM, Lindstrom RT, Hays GC (2014) The accuracy of Fastloc-GPS locations and implications for animal tracking. Methods Ecol Evol 5:1162-1169.

* Elliott KH, McFarlane-Tranquilla L, Burke CM, Hedd A, Montevecchi WA, Anderson WG (2012) Year-long deployments of small geolocators increase corticosterone levels in murres. Mar Ecol Prog Ser 466:1-7

Fossette S, Corbel H, Gaspar P, Le Maho Y, Georges JY (2008) An alternative technique for the long-term satellite tracking of leatherback turtles. Endang Species Res 4:33-41

*Gaos AR, Lewison RL, Yanez IL, Wallace BP and others (2012a) Shifting the life-history paradigm: discovery of novel habitat use by hawksbill turtles. Biol Lett 8: 54-56

*Gaos AR, Lewison RL, Wallace BP, Yanez IL and others (2012b) Spatial ecology of critically endangered hawksbill turtles Eretmochelys imbricata: implications for management and conservation. Mar Ecol Prog Ser 450:181-194

Godley BJ, Lima EHSM, Åkesson S, Broderick AC and others (2003) Movement patterns of green turtles in Brazilian coastal waters described by satellite tracking and flipper tagging. Mar Ecol Prog Ser 253:279-288

* Gutierrez de Velasco G, Winant CD (2004) Wind- and density-driven circulation in a well-mixed inverse estuary. J Phys Oceanogr 34:1103-1116

*Hallworth MT, Mara PP (2015) Miniaturized GPS tags identify non-breeding territories of a small breeding migratory songbird. Sci Rep 5:11069

*Hamelin KM, James MC (2018) Evaluating outcomes of long-term satellite tag attachment on leatherback sea turtles. Anim Biotelem 6:18

Hanson M (2001) An evaluation of the relationship between small cetacean tag design and attachment durations: a bioengineering approach. $\mathrm{PhD}$ dissertation, University of Washington, Seattle, WA

*Hays GC, Christensen A, Fossette S, Schofield G, Talbot J, Mariani P (2014) Route optimisation and solving Zermelo's navigation problem during long distance migration in cross flows. Ecol Lett 17:137-143

* Hazekamp AA, Mayer R, Osinga N (2010) Flow simulation along a seal: the impact of an external device. Eur J Wildl Res 56:131-140

* Hazel J (2009) Evaluation of fast-acquisition GPS in stationary tests and fine-scale tracking of green turtles. J Exp Mar Biol Ecol 374:58-68

Heithaus MR, Frid A, Wirsing AJ, Dill LM and others (2007) State-dependent risk-taking by green sea turtles mediates top-down effects of tiger shark intimidation in a marine ecosystem. J Anim Ecol 76:837-844

Hoerner SF (1993) Fluid dynamic drag. Hoerner Fluid Dynamics, Bakersfield, CA

Jones TT, Van Houton KS, Bostrom BL, Ostafichuk P and others (2013) Calculating the ecological impacts of animal-borne instruments on aquatic organisms. Methods Ecol Evol 4:1178-1186

Kennedy EM, Kemp JR, Mosen CC, Perry GLW, Dennis TE (2015) GPS telemetry for parrots: a case study with the kea (Nestor notabilis). Auk 132:389-396

Koch V, Nichols WJ, Brooks LB (2007) Population ecology of the green/black turtle (Chelonia mydas) in Bahía Mag- 
dalena, Mexico. Mar Biol 153:35-46

Koch V, Peckham SH, Mancini A, Eguchi T (2013) Estimating at-sea mortality of marine turtles from stranding frequencies and drifter experiments. PLOS ONE 8:e56776

Kotliar NB, Wiens JA (1990) Multiple scales of patchiness and patch structure: a hierarchical framework for the study of heterogeneity. Oikos 59:253-260

Kurth S (2007) Ecological assessment of benthic invertebrate assemblages in Laguna San Ignacio, Baja California Sur, Mexico, with special consideration of the grey whale, Eschrichtius robustus, representing a possible external disturbance factor. Diplomarbeit, Bonn University

Kurth S, Megill WM, Yasué M (2008) Preliminary report on the epibenthic and benthic environment of San Ignacio Lagoon. Laguna San Ignacio Wetlands Ecosystem Science Program. www.sanignacioecosystem.org

Logan P, Morreale SJ (1993) Hydrodynamic drag characteristics of juvenile L. kempii, C. mydas, and C. caretta. In: Schroeder BA, Witherington BE (eds) Proc 13th Annu Symp Sea Turtle Biol Conserv, NOAA Tech Memo NMFS-SEFSC-341

López-Castro MC, Koch V, Mariscal-Loza A, Nichols WJ (2010) Long-term monitoring of black turtles Chelonia mydas at coastal foraging areas off the Baja California Peninsula. Endang Species Res 11:35-45

Makowski C, Seminoff JA, Salmon M (2006) Home range and habitat use of juvenile Atlantic green turtles (Chelonia mydas L.) on shallow reef habitats in Palm Beach, Florida, USA. Mar Biol 148:1167-1179

* Mancini A, Koch V, Seminoff JA, Madon B (2012) Smallscale gill-net fisheries cause massive green turtle Chelonia mydas mortality in Baja California Sur, Mexico. Oryx 46:69-77

Nams VO (2006) Improving accuracy and precision in estimating fractal dimension of animal movement paths. Acta Biotheoretica 54:1-11

Nams VO (2013) FRACTAL: a program to analyze the paths of animal movement. Dalhousie University, Halifax. www.dal.ca/faculty/agriculture/plant-food-env/facultystaff/our-faculty/vilis-nams/fractal.html

* Omeyer LCM, Fuller WJ, Godley BJ, Snape RTE, Broderick AC (2019) The effect of biologging systems on reproduction, growth and survival of adult sea turtles. Mov Ecol 7:2

Peckham SH, Maldonado-Diaz D, Walli A, Ruiz G, Crowder LB, Nichols WJ (2007) Small-scale fisheries bycatch jeopardizes endangered Pacific loggerhead turtles. PLOS ONE 10:e1401.

* Phillips RA, Xavier JC, Croxall JP (2003) Effect of satellite transmitters on albatrosses and petrels. Auk 120:1082-1090

Prange HD (1976) Energetics of swimming of a sea turtle. J Exp Biol 64:1-12

Press WH, Teukolsky SA, Vetterling WT, Flannery BP (2007) Numerical recipes: the art of scientific computing, 3rd edn. Cambridge University Press, Cambridge

Schofield G, Bishop CM, MacLean G, Brown P and others (2007) Novel GPS tracking of sea turtles as a tool for conservation management. J Exp Mar Biol Ecol 347:58-68

Schofield G, Bishop CM, Katselidis KA, Dimopoulos P, Pantis JD, Hays GC (2009) Microhabitat selection by sea turtles in a dynamic thermal marine environment. J Anim Ecol 78:14-21

Schofield G, Hobson VJ, Lilley MKS, Katselidis KA, Bishop CM, Brown P, Hays GC (2010) Inter-annual variability in the home range of breeding turtles: implications for current and future conservation management. Biol Conserv
$143: 722-730$

Seminoff JA, Jones TT (2006) Diel movements and activity ranges of green turtles (Chelonia mydas) at a temperate foraging area in the Gulf of California, Mexico. Herpetol Conserv Biol 1:81-86

* Seminoff JA, Resendiz A, Nichols WJ (2002) Home range of green turtles Chelonia mydas at a coastal foraging area in the Gulf of California, Mexico. Mar Ecol Prog Ser 242: 253-265

* Senko J, López-Castro M, Koch V, Nichols WJ (2010a) Immature East Pacific green turtles (Chelonia mydas) use multiple foraging areas off the Pacific coast of Baja California Sur, Mexico: first evidence from mark-recapture data. Pac Sci 64:125-130

* Senko J, Koch V, Megill WM, Carthy RR, Templeton RP, Nichols WJ (2010b) Fine scale daily movements and habitat use of East Pacific green turtles at a shallow coastal lagoon in Baja California Sur, Mexico. J Exp Mar Biol Ecol 391:92-100

* Senko J, Mancini A, Seminoff JA, Koch V (2014) Bycatch and directed harvest drive high green turtle mortality at Baja California Sur, Mexico. Biol Conserv 169:24-30

* Sherrill-Mix SA, James MC (2008) Evaluating potential tagging effects on leatherback sea turtles. Endang Species Res 4:187-193

Southwood AL, Reina RD, Jones VS, Jones DR (2003) Seasonal diving patterns and body temperature of juvenile green turtles at Heron Island, Australia. Can J Zool 81: 1014-1024

Stephens DW, Krebs JR (1987) Foraging theory. Monographs in behavior and ecology. Princeton University Press, Princeton, NJ

* Taquet C, Taquet M, Dempster T, Soria M, Ciccione S, Roos D, Dagorn L (2006) Foraging of the green sea turtle Chelonia mydas on seagrass beds at Mayotte Island (Indian Ocean), determined by acoustic transmitters. Mar Ecol Prog Ser 306:295-302

*van der Hoop J, Corkeron P, Moore M (2017) Entanglement is a costly life history stage in large whales. Ecol Evol 7:92-106

* Vandenabeele SP, Shepard EL, Grogan A, Wilson RP (2012) When three per cent may not be three per cent; deviceequipped seabirds experience variable flight constraints. Mar Biol 159:1-14

*Vincent C, McConnell BJ, Delayat S, Elder JF, Gautier G, Ridoux V (2010) Winter habitat use of harbour seals (Phoca vitulina) fitted with Fastloc TM GPS/GSM tags in two tidal bays in France. NAMMCO Sci Publ 8: 285-302

Watson KP, Granger RA (1998) Hydrodynamic effect of a satellite transmitter on juvenile green turtle (Chelonia mydas). J Exp Biol 201:2497-2505

Weber N, Weber SB, Godley BJ, Ellick J, Witt M, Broderick AC (2013) Telemetry as a tool for improving estimates of marine turtle abundance. Biol Conserv 167:90-96

*Wilson RP, Kreye JM, Lucke K, Urquhart H (2004) Antennae on transmitters on penguins: balancing energy budgets on the high wire. J Exp Biol 207:2649-2662

*Winant CD, Gutierrez de Velasco G (2003) Tidal dynamics and residual circulation in a well-mixed inverse estuary. J Phys Oceanogr 33:1365-1379

*Wood LD, Brunnick B, Milton SL (2017) Home range and movement patterns of subadult hawksbill sea turtles in Southeast Florida. J Herpetol 51:58-67

Zollner PA, Lima SL (1999) Search strategies for landscapelevel interpatch movements. Ecology 80:1019-1030

Submitted: November 26, 2018; Accepted: May 14, 2019

Proofs received from author(s): July 22, 2019 